\title{
Tropical cyclones alter short-term activity patterns of a coastal seabird
}

\author{
Bradley P. Wilkinson ${ }^{1,2^{*}}$, Yvan G. Satgé ${ }^{1,2}$, Juliet S. Lamb ${ }^{3}$ and Patrick G. R. Jodice ${ }^{4,1}$
}

\begin{abstract}
Background: Mobile organisms in marine environments are expected to modify their behavior in response to external stressors. Among environmental drivers of animal movement are long-term climatic indices influencing organism distribution and short-term meteorological events anticipated to alter acute movement behavior. However, few studies exist documenting the response of vagile species to meteorological anomalies in coastal and marine systems.

Methods: Here we examined the movements of Eastern brown pelicans (Pelecanus occidentalis carolinensis) in the South Atlantic Bight in response to the passage of three separate hurricane events in 2 years. Pelicans $(n=32)$ were tracked with GPS satellite transmitters from four colonies in coastal South Carolina, USA, for the entirety of at least one storm event. An Expectation Maximization binary Clustering algorithm was used to discretize pelican behavioral states, which were pooled into 'active' versus 'inactive' states. Multinomial logistic regression was used to assess behavioral state probabilities in relation to changes in barometric pressure and wind velocity.

Results: Individual pelicans were more likely to remain inactive during tropical cyclone passage compared to baseline conditions generally, although responses varied by hurricane. When inactive, pelicans tended to seek shelter using local geomorphological features along the coastline such as barrier islands and estuarine systems.

Conclusions: Our telemetry data showed that large subtropical seabirds such as pelicans may mitigate risk associated with spatially-extensive meteorological events by decreasing daily movements. Sheltering may be related to changes in barometric pressure and wind velocity, and represents a strategy common to several other classes of marine vertebrate predators for increasing survival probabilities.
\end{abstract}

Keywords: Environmental disturbance, EMbC, Hurricane, Seabird, Tracking, Sheltering behavior

\section{Background}

Mobile organisms display common movement syndromes across vertebrate taxa, with movements based on both intrinsic (e.g. body condition) and extrinsic factors (e.g. resource availability) [1]. While intrinsic variation operates on the level of the individual, extrinsic factors acting concurrently on groups of individuals have a role in determining the movement behavior of populations [2]. Among these extrinsic factors in marine and coastal systems are climatic variations that affect distributions on monthly, yearly, or decadal timescales. Long-

\footnotetext{
*Correspondence: bpwilki@g.clemson.edu

'Department of Forestry and Environmental Conservation, Clemson

University, Clemson, SC 29634, USA

${ }^{2}$ South Carolina Cooperative Fish and Wild life Research Unit, Clemson, SC 29634, USA

Full list of author information is available at the end of the article
}

term drivers include extensive and cyclic events such as seasonality [3-5], oscillation events (e.g. El Niño Southern Oscillation) [6, 7], and oceanographic-atmospheric regime coupling [8-11]. Extrinsic drivers of animal movement also occur at more local scales, where acute meteorological events such as storms can influence animal movement from hours to weeks [12, 13]. These short-term events are expected to fluctuate stochastically compared to longer-term climatic drivers, and therefore the extent of and mechanisms by which each affect movement may be variable. While the spatial impacts of macroscale events are relatively well-studied, effects of shorter-term acute drivers (e.g. local storms) are less known [14].

While organisms may respond to seasonally-typical meteorological conditions in repeatable and often predictable

(C) The Author(s). 2019 Open Access This article is distributed under the terms of the Creative Commons Attribution 4.0 International License (http://creativecommons.org/licenses/by/4.0/), which permits unrestricted use, distribution, and 
ways, anomalous conditions offer an opportunity to examine behavioral responses to environmental stressors that occur stochastically [15-17]. Among the most disruptive meteorological events in coastal and marine systems are hurricanes and tropical storms (also called cyclones or typhoons). These spatially-extensive, temporally-focused natural perturbations can affect coastal geomorphology, alter local oceanography, and induce widespread mortality among wildlife populations [18-20]. Typically categorized by relative severity, they are regularly-occurring yet unpredictable phenomena [21]. Hurricanes introduce extreme wind velocities, elevated tidal surges, intense rainfall, widespread flooding, and chaotic sea surface conditions to the local system, and therefore have the potential to reduce organism fitness directly (e.g. mortality events) and indirectly (e.g. reduced foraging opportunities) [22].

Species that occupy ecosystems regularly subjected to hurricanes demonstrate behavioral modifications for increasing survival during cyclonic activity, although direct studies appear limited [14]. For example, marine species commonly display one of two contrasting strategies for mitigating negative effects from intense but shortduration weather events; relocation and sheltering in place. Studies of elasmobranchs (e.g. juvenile blacktip sharks (Carcharhinus limbatus)) have demonstrated increased movement rates upon the approach of a cyclone indicating relocation from shallow nursery areas to deeper, offshore water that is less prone to disturbance [23, 24]. Conversely, Florida manatees (Trichechus manatus latirostris) remain in the same discrete patch during passage of a cyclonic event, with daily movements contained within areas utilized prior to cyclonic exposure [25]. Littoral abundance of sea kraits (Laticauda spp.) in Taiwan appears to be influenced by cyclonic events, with individuals likely seeking shelter among coastal geologic features such as sea caves [26]. Results from loggerhead and hawksbill sea turtles (Caretta caretta and Eretmochelys imbricate, respectively) indicate marked changes in swimming and diving behavior during storm interaction, although with variable and sometimes contrasting responses depending on breeding stage [27-29].

Of particular utility for examining differential responses to cyclonic events, seabirds present a group of taxonomically and morphologically diverse organisms often impacted by marine storms. For example, smallerbodied pelagic seabirds may attempt to avoid or circumnavigate an approaching hurricane [14, 30]. Individuals unable to do so may be displaced far from their preferred habitat (often inland), leading to the observed wrecks of these species following major events (e.g. [31]). Conversely, larger-bodied coastal-dwelling species may reduce daily activities and attempt to shelter during storm passage, but this remains unexamined. Variation in hurricane response may also differ by life stage in addition to morphology [14]. Understanding how various seabird species respond to large-scale environmental irregularities may therefore clarify apparent discrepancies in displacement susceptibility [30]. However, due to the stochastic and unpredictable nature of hurricane events, as well as the difficulties and dangers of collecting data on animal movement during these times, published literature is lacking on this topic particularly for largerbodied coastal-dwelling species.

As part of ongoing research examining movement patterns of Eastern brown pelicans (Pelecanus occidentalis carolinensis) in the South Atlantic Bight, we report the behavioral strategies utilized by two cohorts of satellitetracked individuals in coastal South Carolina and Georgia during the passage of three hurricane events. The Eastern brown pelican is a large-bodied coastal seabird with breeding colonies distributed along barrier and estuarine islands ranging from tropical to temperate waters of the western North Atlantic. As a facultative migrant, the brown pelican displays a range of individual post-breeding movement strategies [32], which when combined with timing of departure and location of breeding colony, annually exposes many individuals to potential cyclonic events throughout their range. During peak hurricane activity in the South Atlantic Bight (late August to September), adult pelicans may variably disperse from the breeding colony but are generally not yet engaged in migratory behavior (B.W. pers. obs.). We hypothesized that the movement behavior of individual pelicans would correlate with meteorological condition during passage of a hurricane by either (a) increasing movement activity and fleeing the storm or (b) decreasing movement activity and sheltering in place.

\section{Methods}

\section{Study area}

We conducted our study in the South Atlantic Bight, USA, which extends from the Cape Fear River Basin to approximately Cape Canaveral (Fig. 1). The coast here is characterized by a complex geomorphology of barrier islands, estuaries, and salt marshes. The area supports ca. 15 brown pelican colonies annually (active breeding from April - September) and many of the beaches and islands are used as migratory stopover, staging, or wintering grounds for this species and others [33].

\section{Satellite transmitter deployments}

Nesting pelicans were outfitted with GPS satellite transmitters (GeoTrak Inc., North Carolina, USA) at four colonies in coastal South Carolina (Bird Key Stono, 32 $38^{\prime} \mathrm{N}, 79^{\circ} 58^{\prime}$ $\mathrm{W}, n=21$; Castle Pinckney, $32^{\circ} 46^{\prime} \mathrm{N}, 79^{\circ} 54^{\prime} \mathrm{W}, n=12$; Marsh Island, $32^{\circ} 59^{\prime} \mathrm{N}, 79^{\circ} 33^{\prime} \mathrm{W}, n=7$; Deveaux Bank, $\left.32^{\circ} 32^{\prime} \mathrm{N}, 80^{\circ} 10^{\prime} \mathrm{W}, n=5\right)$. Colony size ranged from ca. 50-2000 pairs. Deployments commenced during the chick- 


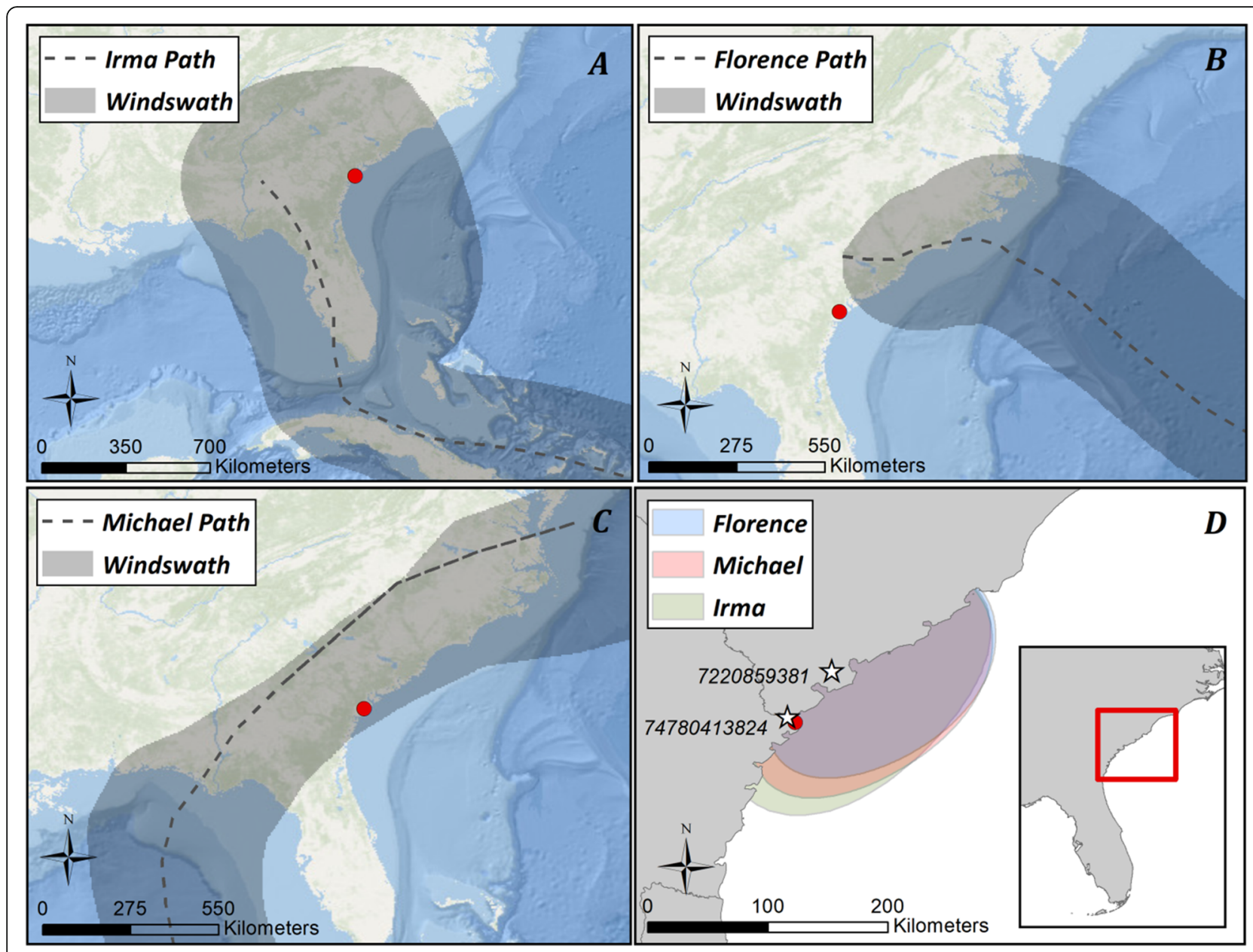

Fig. 1 Path and windswath extent of Hurricanes Irma (a), Florence (b), and Michael (c) in the South Atlantic Bight with (d) 25\% utilization distribution obtained from kernel density analysis of tracked pelicans during the month corresponding to the passage of each hurricane. White stars represent locations of meteorological data collection, with NOAA station identification numbers. Red dots represent Savannah, Georgia, USA. Hurricane data obtained from the NOAA National Hurricane Center and Central Pacific Hurricane Center (https://www.nhc.noaa.gov/gis/)

rearing stage (May-July) of the 2017 and 2018 breeding seasons. Transmitters weighed $\sim 65 \mathrm{~g}(10 \times 3.5 \times 3 \mathrm{~cm})$ and constituted $\leq 3 \%$ body mass of instrumented individuals (range $=2475-4350 \mathrm{~g})$, the recommended threshold for large seabirds [34]. Briefly, nest-attending adults were captured via either neck or leg noose and equipped with a solar GPS Platform Terminal Transmitter dorsally using a backpack-style harness system. For a description of specific attachment procedures, see [35]. During the post-breeding stage of deployment (September - November), units were programmed to record 10 locations per day at $90 \mathrm{~min}$ intervals between the hours of 01:00-23:30 GMT and were dutycycled on an $8 \mathrm{~h}$ on to $36 \mathrm{~h}$ off activity schedule. Unit error was assumed to be similar to that of [32], i.e. $4.03 \pm 2.79 \mathrm{~m}$.

\section{Hurricane events}

Our opportunistic analysis of pelican movement in relation to hurricane activity includes three storm events. On 10 September 2017, Hurricane Irma made landfall in southwestern Florida, USA, as a Category 4 tropical cyclone. Over the subsequent 1.5 days, Irma proceeded north along the coast of western Florida before weakening and degenerating near the central Georgia-Alabama border. Although the storm was centered mainly along the Gulf coast of Florida, much of the southeastern Atlantic seaboard was affected by the outer cyclonic bands (Fig. 1).

Hurricane Florence made landfall on 14 September 2018 in southern North Carolina, USA, as a reduced Category 1 tropical cyclone, having been a Category 4 cyclone 4 days prior. Florence tracked inland in a southeasterly direction as it weakened, degenerating over West Virginia, USA, three days after landfall, affecting predominantly the coastal Carolinas (Fig. 1).

Less than 1 month later, Hurricane Michael made landfall in the panhandle of Florida on 10 October 2018 as a Category 4 tropical cyclone. Michael followed a northeasterly trajectory after landfall, weakening incrementally over 
the southeastern United States before restructuring as an extratropical cyclone 2 days later off the Mid-Atlantic coast (Fig. 1). Similar to Irma, Michael impacted much of the Atlantic seaboard due to the trajectory, strength, and spatial extent of the storm.

\section{Meteorological data}

A kernel density analysis was used to identify the core spatial area utilized by instrumented pelicans during each hurricane event. Subsequent utilization distributions (UDs) were used to determine a representative location for assessing pelican response to meteorological indices. This approach allowed for the acquisition of meteorological data that would represent shared conditions for the greatest number of individuals throughout the tracking period. We used only locations recorded during the calendar month of the respective hurricane event, which corresponded with peak cyclonic activity but limited seasonal changes in weather. Distributions therefore reflected core use areas during the entire passage of the cyclone as well as the remainder of the month in which the cyclone occurred. Erroneous locations were identified and removed through a combination of visual inspection (e.g. consecutive locations separated by unrealistic distances) and a speed filter of $\geq 65 \mathrm{~km}$ per hour [36]. Kernel bandwidth was determined using $\mathrm{R}$ statistical software ( $\mathrm{v}$ 3.4.2.) through a plug-in bandwidth selector in package ks [37]. Locations within the $25 \%$ UD (i.e. core range) identified in the kernel density output during the month of each respective hurricane (grid $=400$, extent $=0.4^{\circ}$ ) were then used to assess movement patterns in relation to storm events. Roughly, the area of highest use by pelicans during these time periods paralleled the coastline from central South Carolina to north-central Georgia (Fig. 1). Individual pelicans located outside of the prior $25 \%$ UD at the time of hurricane passage (e.g. in Chesapeake Bay) were manually excluded from further analysis, as well as individuals for whom movement data was not complete for the entire time period.

Meteorological data were obtained via the National Oceanic and Atmospheric Administration (NOAA) National Centers for Environmental Information from the Hunter U.S. Army Airfield, Savannah, Georgia (station 74780413824), to represent conditions experienced during Hurricane Irma, and from the Marine Corps Air Station Beaufort, Beaufort, South Carolina (station 72208593831), to represent conditions during Hurricanes Florence and Michael (https://www.ncdc.noaa.gov/ ). These sites were within the $25 \%$ UD in the kernel density analysis. Although spatially similar, multiple weather locations were required as neither station had complete data for all three hurricane events in totality. Meteorological data were collected hourly and spanned the entire month of each cyclonic event. Data were requested 04 November 2017, 28 November 2018, and 12 December 2018, respectively.

\section{Behavioral clustering}

We used an Expectation Maximization binary Clustering $(\mathrm{EMbC})$ algorithm to derive biologically-relevant behavioral states for individual brown pelicans [38]. EMbC uses unsupervised relationships between successive locations incorporating path distance and tortuosity (i.e. velocity and turning angle) to infer underlying behavioral processes. EMbC is particularly appropriate for remotely-sensed location data as it accounts for spatial and temporal correlations and uncertainties in the input features and is robust to spatial data collected at relatively long intervals [39]. Critically, EMbC is capable of producing biologically-relevant classifications for locational data recorded at timescales relevant to the current study (e.g. [40]). Each point within individual tracks was clustered into one of four categories: low velocity/ low turning angle (LL), low velocity/ high turning angle (LH), high velocity/ low turning angle (HL), and high velocity/ high turning angle (HH) (Fig. 2). These four behavioral nodes were biologically interpreted as corresponding to inactive, localized search, commuting, and dispersive search behaviors, respectively. Following [38], a post-processing smoothing procedure was applied based on consecutive behavioral correlations to manage temporally-irregular data. This smoothing procedure searches for clusters of the same behavioral assignment that contain a single point of a different classification, and adds additional likelihood weight to that single point belonging to the larger cluster, a feature explicitly implemented in state-space models. In this way, the smoothing procedure favors homogenized bouts of behavior instead of single-point behavioral switches during clusters of equal assignment. We also calculated mean step length (distance between successive points) and net displacement (maximum distance from the first location in the series) for descriptive purposes. Each point was finally matched temporally to the closest hourly meteorological variable for statistical analysis.

\section{Statistical analyses}

We assessed the effects of meteorological drivers on pelican behavioral state with multinomial logistic regression following [41]. To simplify model interpretation and to examine activity patterns more accurately matched to the temporal resolution of the data, models were conducted on a reduced set of two behavioral nodes classified as either active (including localized search, commuting, and dispersive search; LH, HL, and $\mathrm{HH}$, respectively) or inactive (LL). Environmental variables of interest (barometric pressure and wind velocity) were chosen a priori based on data completeness, 


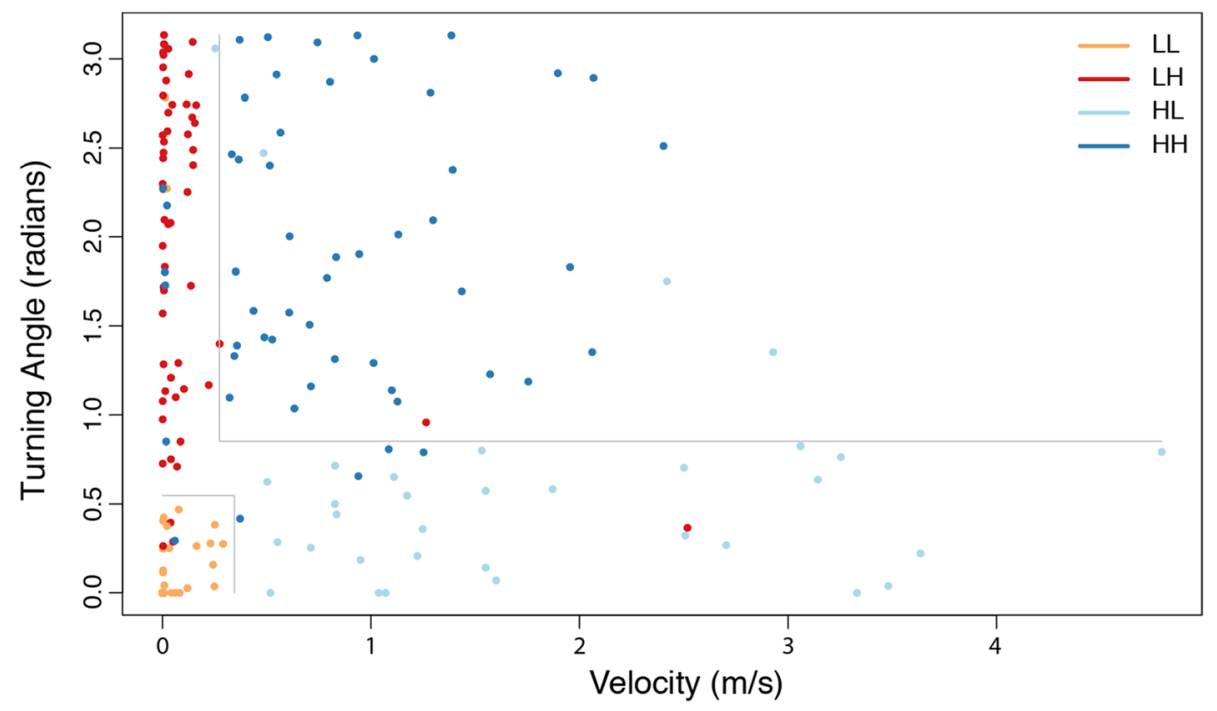

Fig. 2 Example scatterplot of Expectation Maximization binary Clustering (EMbC) discretization for one individual Eastern brown pelican in the South Atlantic Bight from 6 to 24 September 2017. Gray lines represent delimiters for categorizing the four possible behavioral states. Note that delimiters do not determine a perfect partition of the variable space, and therefore do not converge perfectly on a graphical plane. Additionally, some points are within the delimiters of separate behavioral states; this is a result of the applied smoothing parameter. See [38] for additional details. All points labeled LH, HL, and $\mathrm{HH}$ represent active states; $\mathrm{LL}$ represents an inactive state

relevance to cyclonic activity, and probability of being sensed by individual pelicans [14].

Both tracking and meteorological data were further subset to exclude other potentially confounding anomalous conditions. We defined an anomalous event as a barometric pressure reading $\geq 1 \mathrm{SD}$ from the monthly mean. Only data collected from the end of the last pressure anomaly precyclone to the first pressure anomaly post-cyclone were therefore included in our regression analysis, thus creating a temporal segment of activity that was exclusively characterized by 'baseline' conditions with the exception of the cyclonic event. Significant differences of barometric pressure and wind velocity between study periods were assessed via Kruskal-Wallis chi-squared tests, with Wilcoxon rank sum tests used when significant differences were found.

Four multinomial logistic regression models were fit to the data using $\mathrm{R}$ package mlogit [42], including a null model, single-effect wind velocity model, single-effect barometric pressure model, and global model including both wind velocity and barometric pressure. Model selection was performed within each set using Akaike's Information Criterion (AIC), with the best-performing model indicated by the lowest AIC value. Given low AIC similarity between models, we did not model average. Environmental variables were interpreted as having a significant effect on individual behavioral states at $p<0.05$. We further assessed transition probabilities using the top-performing model, with the null state (i.e., reference level) defined as inactive (i.e., the probabilities are reflective of transitioning from inactivity to activity).

\section{Results}

After removal of individuals with incomplete tracks and those located outside of the 25\% UD, 32 instrumented Eastern brown pelicans remained in the sample population for Hurricanes Irma $(n=18)$, Florence $(n=16)$, and Michael $(n=12)$. Due to the multi-year duration of tag deployment as well as the temporal spacing of cyclonic events, some individuals were tracked for more than one event ( 2 events, $n=8$; 3 events, $n=3$ ).

Hourly barometric pressure and wind velocity were relatively consistent throughout each defined study period with the exception of hurricane passage (Fig. 3). Local minima of barometric pressure and local maxima of wind velocity were both greater than one standard deviation away from the monthly mean during the day that the center of the storm passed through the study area (Table 1), indicating anomalous conditions.

Barometric pressures were significantly different during each period of study (Kruskal-Wallis $\chi^{2}=442.27, p<0.001$ ), with lower values during Hurricane Irma than Hurricanes Florence (Wilcoxon rank sum test $Z=-5.26, p<0.001$ ) and Michael $(Z=-18.66, p<0.001)$, and significantly lower values during Hurricane Florence than Hurricane Michael $(Z=-16.19, p<0.001)$. Significant differences likewise existed between measured wind velocities (Kruskal-Wallis $\chi^{2}=15.89, p<0.001$ ), but not between every event. Wind velocities were higher during Hurricane Irma than Hurricanes Florence (Wilcoxon rank sum test $Z=-3.39, p<$ $0.001)$ and Michael $(Z=-2.39, p=0.017)$, but wind velocities between Hurricane Florence and Hurricane Michael were not significantly different $(Z=-1.66, p=0.096)$. 

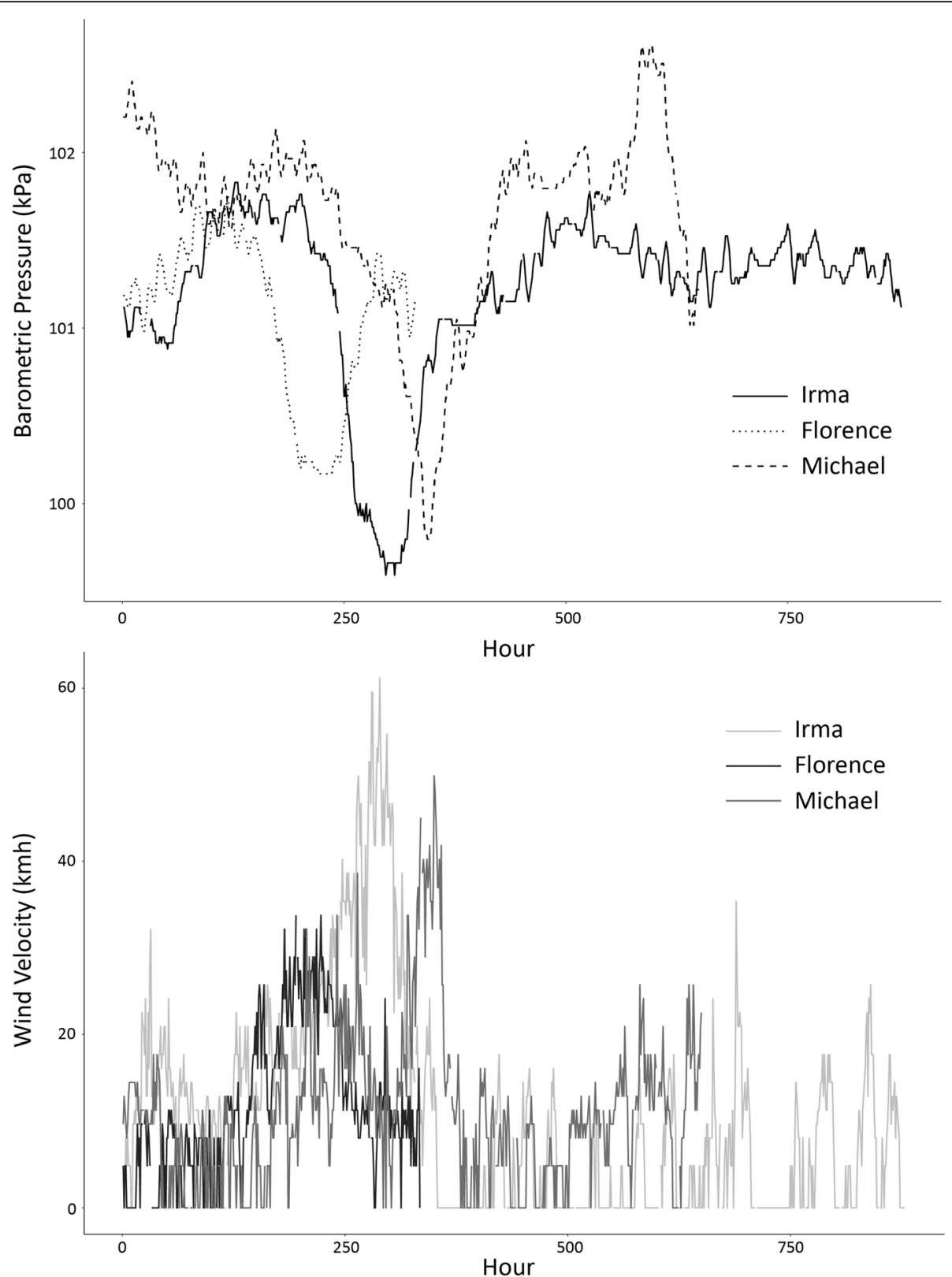

Fig. 3 Hourly barometric pressure and wind velocity recorded during the study period of Hurricanes Irma, Florence, and Michael. Solid or light grey lines represent Irma, dotted or black lines represent Florence, and dashed or medium grey lines represent Michael, respectively

Table 1 Summary of meteorological data for each cyclonic event in the South Atlantic Bight from 2017 to 2018 with the number of pelican locations recorded during each study period (temporal range of 'baseline' conditions, defined in-text)

\begin{tabular}{lllllll}
\hline Cyclone & BP Monthly Mean $(\mathrm{kPa})$ & BP Minimum $(\mathrm{kPa})$ & WV Monthly Mean $(\mathrm{km} / \mathrm{h})$ & WV Maximum $(\mathrm{km} / \mathrm{h})$ & Study Period & Locations $(n)$ \\
\hline Irma & $101.25 \pm 0.43^{\mathrm{a}}$ & $99.59^{\mathrm{a}}$ & $10.4 \pm 10.9^{\mathrm{a}}$ & $61.2^{\mathrm{a}}$ & $6-24$ Sept. 2017 & 2901 \\
Florence & $101.56 \pm 0.49^{\mathrm{b}}$ & $100.17^{\mathrm{b}}$ & $10.2 \pm 7.2^{\mathrm{b}}$ & $33.8^{\mathrm{b}}$ & $9-18$ Sept. 2018 & 1323 \\
Michael & $101.63 \pm 0.58^{\mathrm{c}}$ & $99.80^{\mathrm{c}}$ & $11.3 \pm 8.4^{\mathrm{b}}$ & $49.9^{\mathrm{b}}$ & $1-20$ Oct. 2018 & 2124 \\
\hline
\end{tabular}

$B P=$ barometric pressure, $W V=$ wind velocity. Letters within each column indicate significant differences between study periods based on Wilcoxon rank sum test 
Pelicans tended to make relatively short daily movements during each period of analysis, and these movements were typically $\leq 5 \mathrm{~km}$ seaward from the immediate coastline ( $\underline{x}$ step length $=3.8 \pm 7.1 \mathrm{~km}$, range $=0-94.9$ $\mathrm{km})$. Individual pelicans displayed both sedentary and dispersive behavior at the regional level, consistent with individual variation in post-breeding dispersal $(\underline{x}$ net displacement $=51.7 \pm 69.0 \mathrm{~km}$, range $=0-267.4 \mathrm{~km})$. Behavioral assignments discretized by the EMbC algorithm were more likely to be in active state $(66.1 \pm 17.9 \%)$ than in inactive state $(33.4 \pm 17.8 \%)$. Multinomial logistic regression and AIC-driven model selection indicated global models (i.e., barometric pressure + wind speed) as best candidates for explaining pelican behavioral state probabilities during both Hurricanes Irma and Florence $\left(\Delta \mathrm{AIC}_{\mathrm{c}}=11.52\right.$ and 9.38, respectively $)$. Both the global model and a model including only wind speed were selected as best candidates during Hurricane Michael $\left(\triangle \mathrm{AIC}_{\mathrm{c}}=1.51\right)$.

During Hurricane Irma, individuals were significantly more likely to transition from an inactive state to an active state when barometric pressure increased, but were significantly more likely to remain in an inactive state when wind velocity increased (Table 2). The odds of an individual transitioning from an inactive state to an active state decreased by 0.91 for every unit decrease in barometric pressure while the odds of an individual transitioning from an inactive state to an active state decreased by 0.84 for every unit increase in wind velocity. During Hurricane Florence, individuals were significantly more likely to transition from an inactive state to an active state given an increase in barometric pressure as well as an increase in wind velocity (Table 2). The odds of an individual transitioning from an inactive state

Table 2 Results of pooled behavioral state modeling using multinomial logistic regression in relation to environmental variables representing passage of Hurricanes Irma (I), Florence $(\mathrm{F})$, and Michael (M)

\begin{tabular}{|c|c|c|c|}
\hline Variable & Coefficient & Standard Error & t-value \\
\hline Intercept $(\mathrm{I})^{* *}$ & 0.9991 & 0.0424 & 23.5649 \\
\hline $\begin{array}{l}\text { Barometric } \\
\text { Pressure }(I)^{*}\end{array}$ & 0.0978 & 0.0462 & 2.1166 \\
\hline Wind Speed $(I)^{* *}$ & -0.1744 & 0.0474 & -3.6760 \\
\hline Intercept $(F)^{* *}$ & 0.6370 & 0.0584 & 10.9010 \\
\hline $\begin{array}{l}\text { Barometric } \\
\text { Pressure }(F)^{* *}\end{array}$ & 0.2600 & 0.0776 & 3.3498 \\
\hline Wind Speed $(F)^{*}$ & 0.1822 & 0.0780 & 2.3360 \\
\hline Intercept $(M)^{* *}$ & 0.3678 & 0.0443 & 8.2979 \\
\hline $\begin{array}{l}\text { Barometric } \\
\text { Pressure (M) }\end{array}$ & -0.0872 & 0.0466 & -1.8701 \\
\hline Wind Speed $(M)^{*}$ & -0.1088 & 0.0467 & -2.3314 \\
\hline
\end{tabular}

to an active state decreased by 0.77 for every unit decrease in barometric pressure and increased by 1.20 for every unit increase in wind velocity. According to the global model, during Hurricane Michael individuals were significantly more likely to remain in an inactive state given an increase in wind velocity (Table 2). There was no significant relationship between barometric pressure and activity. The intercept was the only significant coefficient in the model that included only wind speed, and is therefore not reported. The odds of an individual transitioning from an inactive state to an active decreased by 0.90 for every unit increase in wind velocity.

\section{Discussion}

Based on results from EMbC analysis and multinomial logistic regression, we demonstrate that Eastern brown pelicans in the South Atlantic Bight respond to the passage of spatially-extensive cyclonic events by increasing time of inactivity, regardless of initial landfall proximity. We also found that barometric pressure and wind velocity were significant predictors of behavioral state, indicating that individuals may adjust their behavior in response to meteorological changes associated with storm conditions.

Among several classes of marine taxa, perturbations in barometric pressure appear to be a consistent predictor of behavioral change during storm events $[23,24,26,43]$. Evidence from terrestrial ecosystems also indicate that some bird species adjust their behavior in response to sudden decreases in atmospheric pressure. For example, [44] demonstrated that declining barometric pressure instigated an increase in food intake for captive white-crowned sparrows (Zonotrichia leucophrys). Similar results were obtained by [45] in white-throated sparrows (Zonotrichia albicollis). Our data suggest that pelicans likewise modify their behavior given sudden decreases in barometric pressure. Although fine scale fluctuations in absolute pressure may not be meaningful, or possibly even detectable, precipitous declines like those experienced during cyclonic events could indicate environmental conditions detrimental to individual condition.

Our results also show a strong predictive relationship between wind velocity and behavioral state in brown pelicans. Although wind velocity is infrequently considered as a driver of behavioral changes in strictly aquatic species compared to barometric pressure, it is reasonable to conclude that avian species requiring flight to forage or relocate would be especially sensitive to anomalous wind conditions. Observations of the movements of redfooted boobies (Sula sula) and great frigatebirds (Fregata minor) during cyclonic activity in the Southern Hemisphere suggest that individuals of these species are able to detect approaching gale-force winds as an indicator of an impending cyclone and utilize them for avoidance 
behavior, although this relationship was not explored quantitatively [14]. In contrast to more pelagic species, pelican locomotion may be hampered by severely elevated wind velocities [46, 47], precluding avoidance behavior. Intrinsic differences in wing morphology (i.e. aspect ratio) and flight characteristics support this differential response in flight to increasing wind conditions [48], although life stage and breeding status may be relevant as well [14].

Model results suggest that behavioral responses to storm activity may also vary with the magnitude of the storm itself. Of the three cyclonic events we assessed, meteorological conditions during Hurricane Irma included the highest and lowest absolute values for wind velocity and barometric pressure, respectively, and were significantly different from both Florence and Michael. These anomalous conditions were also maintained over a longer duration of time compared to other events. Our models for pelican behavior during Hurricane Irma indicated that both low barometric pressure and high wind velocity were highly significant predictors of inactivity; however, this trend differed among cyclonic events (Table 2). For example, pelicans experienced significantly lower wind velocities during Hurricane Florence and for a shorter duration. As such, our models showed a positive relationship between wind speed and activity, but this may be an artefact of the overall lower magnitude of wind velocity change from baseline during the event period. Similarly, Hurricane Michael was characterized by a moderate but relatively sudden decrease in barometric pressure, and models indicated an unexpected negative relationship with pelican activity (Fig. 3). It should be noted, however, that this term was nonsignificant in the top model and that a model including only wind velocity was also highly supported. We posit that cyclone characteristics contribute significantly to the degree of behavioral modification among individuals, and that events with a higher magnitude of change from 'baseline' over a longer period of time, such as experienced during Hurricane Irma, result in a greater reduction of activity than comparably weaker events. Events of greater magnitude may be more easily sensed by pelicans and with greater certainty of producing inclement conditions, eliciting a more detectable behavioral response.

Alternative sources of variation in model coefficients include sample size discrepancies, manifested as 'pelican-hours' (i.e., the number of tracked pelicans multiplied with the number of hours of each study period). For example, fewer individual pelicans were tracked during Hurricane Florence $(n=15)$ in comparison to Hurricane Irma $(n=18)$, exacerbated by a 10 -day study period compared to a 19-day study period, respectively. This resulted in over twice as many 'pelican-hours' and subsequent behavioral classification points for Hurricane Irma than Florence, potentially adding greater resolution to behavioral contrasts between hurricane and nonhurricane time series. Models may also be sensitive to the magnitude of behavioral change displayed during different events, with comparatively weak reductions in activity being undetected. Additional data would therefore be required to determine if spatial sampling rate during data collection or storm characteristics (e.g. duration and intensity) would have greater influence on the magnitude of behavioral change detectable during future cyclonic events.

Timing of cyclones with respect to date and stage of the breeding cycle may also affect the overall activity rates. While Hurricanes Irma and Florence both occurred in early-to-mid September (soon after the end of chickrearing), Hurricane Michael made landfall in early October, nearly a full month later in the annual cycle. Pelicans may endogenously be less active during later months as temperatures drop and energy maintenance becomes more prominent, but this requires further study, as does the extent of post-fledging care in this species.

Access to readily-available refugia in the form of barrier islands and estuarine systems may also positively act upon coastal seabirds to remain stationary during extreme meteorological conditions (Fig. 4). As strictly pelagic seabird species typically remain offshore for resource acquisition, access to shelter during the passage of a hurricane is functionally negligible. It is unclear whether pelagic species would attempt resting on the surface of the water as a sheltering strategy, given the likely turbulent conditions, probable reduction in foraging opportunity, and ability to maintain efficient flight even during severe wind conditions. Indeed, some tropical species appear to make use of terrestrial structures when cyclones approach breeding colonies and access to refugia is available, yet display avoidance behavior when encountering a cyclone at sea [14]. Visual inspection of pelican tracks indicate a frequent use of protected estuarine habitats during severe storms, although further analysis of habitat associations is needed to determine the magnitude and significance of these relationships.

Lastly, the behavioral changes described in the present study occurred during cyclonic events that only indirectly impacted core-use areas. This indicates that the effects of hurricanes on coastal and marine taxa may extend well beyond those habitats centered on the eye of the storm. If changing global climate precipitates hurricanes of greater spatial extent [49], impacts to wildlife may be more widespread than previously reported.

\section{Conclusion}

Hurricanes are acute meteorological disturbances that can act as significant environmental stressors to coastal and marine organisms. Despite the potential fitness consequences that they incur, species have adapted to the 

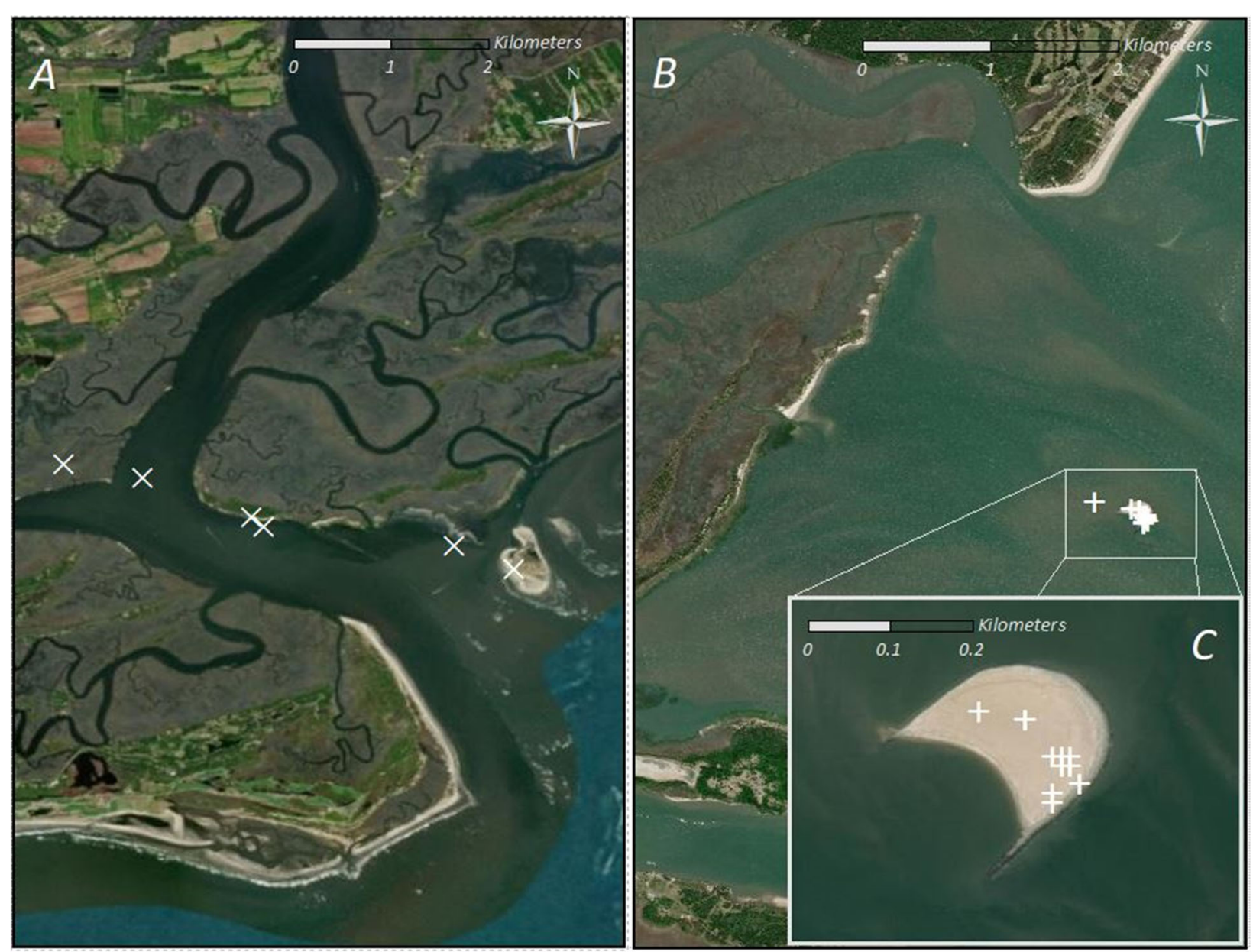

Fig. 4 Example habitats used by Eastern brown pelicans during the passage of Hurricane Irma through the South Atlantic Bight on 11 September 2017. a Individual pelican moving progressively inland up a coastal river, settling on both a barrier island and in an estuary. b Individual pelican sheltering on a small barrier island for the duration of the cyclone, with $\mathbf{c}$ inset of the island

presence of episodic cyclonic events through behavioral modification and risk mitigation strategies. For Eastern brown pelicans in the South Atlantic Bight, this mitigation appears to be achieved through a decrease in movement and a prolonged maintenance of inactive behavior. These periods of rest occur in natural coastal structures such as barrier islands and estuarine systems, which provide shelter from many of the direct effects of hurricane exposure. While this strategy may be prevalent for large, coastal-dwelling seabirds, it is likely vastly different from strategies employed by other seabird guilds and by other marine vertebrate taxa, particularly those frequenting pelagic systems. Increased examination of animal movement responses to cyclonic events would greatly advance our understanding of how mobile organisms utilize behavioral modification to manage spatially-extensive environmental stressors, particularly in the face of climate change and the potential consequences for increased disruption therein.

\section{Abbreviations}

AIC: Akaike's Information Criterion; EMbC: Expectation Maximization binary Clustering; G: Grams; HH: High velocity/ high turning angle; HL: High velocity/ low turning angle; Kmh: Kilometers per hour; KPa: Kilopascal; LH: Low velocity/ high turning angle; LL: Low velocity/ low turning angle; M: Meters; Min: Minutes; SD: Standard deviation; UD: Utilization distribution

\section{Acknowledgements}

We would like to thank Sons of Confederate Veterans for access to Castle Pinckney and St. Johns Yacht Harbor for logistical support. Felicia Sanders, Janet Thibault, and Janelle Ostroski provided assistance in the field. Emma Kelsey provided an internal review of the manuscript for the U.S. Geological Survey. The South Carolina Cooperative Fish and Wildlife Research Unit is jointly supported by the U.S. Geological Survey, South Carolina DNR, and Clemson University. Any use of trade, firm, or product names is for descriptive purposes only and does not imply endorsement by the U.S. Government.

\section{Authors' contributions}

BW and PJ conceived the ideas and designed methodology; BW, YS, and JL collected the data; BW analysed the data; BW and PJ led the writing of the manuscript. All authors contributed critically to the drafts and gave final approval for publication. 


\section{Funding}

Funding was provided by the U.S. Geological Survey Ecosystems Mission Area, and facilitated by Mona Khalil (USGS).

\section{Availability of data and materials}

Data supporting this manuscript is available at www.sciencebase.gov, DOl: https://doi.org/10.5066/P9D5IP0G.

\section{Ethics approval}

Field research was conducted with permission from the Clemson University Animal Care and Use Committee (2017-008). Permitting for field data collection was provided by the U.S. Geological Survey Bird Banding Lab (22408) and South Carolina Department of Natural Resources (BB-18-22).

\section{Consent for publication}

Not applicable.

\section{Competing interests}

The authors declare that they have no competing interests.

\section{Author details}

'Department of Forestry and Environmental Conservation, Clemson University, Clemson, SC 29634, USA. ${ }^{2}$ South Carolina Cooperative Fish and Wildlife Research Unit, Clemson, SC 29634, USA. ${ }^{3}$ Department of Natural Resource Science, University of Rhode Island, Kingston, RI 02881, USA. ${ }^{4}$ U.S. Geological Survey South Carolina Cooperative Fish and Wildlife Research Unit, Clemson, Clemson, SC 29634, USA.

\section{Received: 7 July 2019 Accepted: 9 October 2019}

\section{Published online: 28 October 2019}

\section{References}

1. Abrahms B, Seidel DP, Dougherty E, Hazen EL, Bograd SJ, Wilson AM, et al. Suite of simple metrics reveals common movement syndromes across vertebrate taxa. Mov Ecol. 2017:5:12.

2. Nathan R, Getz WM, Revilla E, Holyoak M, Kadmon R, Saltz D, Smouse PE. A movement ecology paradigm for unifying organismal movement research. Proc Natl Acad Sci. 2008;105(49):19052-9.

3. Bocher $P$, Labidoire $B$, Cherel $Y$. Maximum dive depths of common diving petrels (Pelecanoides urinatrix) during the annual cycle at Mayes Island Kerguelen. J Zool. 2000;251(4):517-24.

4. OToole MD, Lea M-A, Guinet C, Schick R, Hindell MA. Foraging strategy switch of a top marine predator according to seasonal resource differences. Front Mar Sci. 2015;2(21):1-10.

5. Xavier JC, Louzao M, Thorpe SE, Ward P, Hill C, Roberts D, Croxall JP, Phillips RA. Seasonal changes in the diet and feeding behaviour of a top predator indicate a flexible response to deteriorating oceanographic conditions. Mar Biol. 2013;160(7):1597-606

6. Crocker DE, Costa DP, Le Boeuf BJ, Webb PM, Houser DS. Impact of El Niño on the foraging behavior of female northern elephant seals. Mar Ecol Prog Ser. 2006:309:1-10

7. Thorne LH, Conners MG, Hazen EL, Bograd SJ, Antolos M, Costa DP, Shaffer SA. Effects of El Niño-driven changes in wind patterns on North Pacific albatrosses. J R Soc Interface. 2016;13(119):20160196.

8. Bond AL, Jones IL, Sydeman WJ, Major HL, Minobe S, Williams JC, Byrd GV. Reproductive success of planktivorous seabirds in the North Pacific is related to ocean climate on decadal scales. Mar Ecol Prog Ser. 2011; 424:205-18.

9. Louzao M, Aumont O, Hothorn T, Wiegand T, Weimerskirch H. Foraging in a changing environment: habitat shifts of an oceanic predator over the last half century. Ecography. 2013;36(1):057-67.

10. Weimerskirch $H$, Louzao M, de Grissac S, Delord K. Changes in wind pattern alter albatross distribution and life-history traits. Science. 2012; 335(6065):211-4.

11. Weise MJ, Costa DP, Kudela RM. Movement and diving behavior of male California Sea lion (Zalophus californianus) during anomalous oceanographic conditions of 2005 compared to those of 2004. Geophys Res Lett. 2006;33:L22S10.

12. Spruzen FL, Woehler EJ. The influence of synoptic weather patterns on the at-sea behaviour of three species of albatross. Polar Biol. 2002;25:7.
13. Weimerskirch H, Guionnet T, Martin J, Shaffer SA, Costa DP. Fast and fuel efficient? Optimal use of wind by flying albatrosses. Proc Biol Sci. 2000; 267(1455):1869-74.

14. Weimerskirch $H$, Prudor A. Cyclone avoidance behaviour by foraging seabirds. Sci Rep. 2019;9(1):5400.

15. Senner NR, Verhoeven MA, Abad-Gómez JM, Gutiérrez JS, Hooijmeijer JCEW, Kentie R, Masero JA, Tibbitts TL, Piersma T. When Siberia came to the Netherlands: the response of continental black-tailed godwits to a rare spring weather event. J Anim Ecol. 2015;84(5):1164-76.

16. Wilson UW. The effect of the 1997-1998 El Nino on Rhinoceros auklets on Protection Island, Washington. Condor. 2004;107(January):18-20.

17. Zhou Y, Newman C, Chen J, Xie Z, Macdonald DW. Anomalous, extreme weather disrupts obligate seed dispersal mutualism: snow in a subtropical forest ecosystem. Glob Chang Biol. 2013;19(9):2867-77.

18. Huang RM, Bass OL Jr, Pimm SL. Sooty tern (Onychoprion fuscatus) survival, oil spills, shrimp fisheries, and hurricanes. PeerJ. 2017;5:e3287.

19. Marsh CP, Wilkinson PM. The impact of hurricane Hugo on coastal bird populations. J Coast Res. 1991;8(8):327-34.

20. Nicoll MAC, Nevoux M, Jones CG, Ratcliffe N, Ruhomaun K, Tatayah V, Norris K. Contrasting effects of tropical cyclones on the annual survival of a pelagic seabird in the Indian Ocean. Glob Chang Biol. 2017;23(2):550-65.

21. Weinkle J, Maue R, Pielke R. Historical global tropical cyclone landfalls. J Clim. 2012;25(13):4729-35.

22. Dewald JR, Pike DA. Geographical variation in hurricane impacts among sea turtle populations. J Biogeogr. 2014;41(2):307-16.

23. Heupel MR, Simpfendorfer CA, Hueter RE. Running before the storm: Blacktip sharks respond to falling barometric pressure associated with tropical storm Gabrielle. J Fish Biol. 2003;63(5):1357-63.

24. Udyawer V, Chin A, Knip DM, Simpfendorfer CA, Heupel MR. Variable response of coastal sharks to severe tropical storms: environmental cues and changes in space use. Mar Ecol Prog Ser. 2013;480:171-83.

25. Langtimm CA, Krohn MD, Reid JP, Stith BM, Beck CA. Possible effects of the 2004 and 2005 hurricanes on manatee survival rates and movement. Estuar Coasts. 2006;29(6):1026-32

26. Liu YL, Lillywhite HB, Tu MC. Sea snakes anticipate tropical cyclone. Mar Biol. 2010:157(11):2369-73.

27. Sakamoto W, Uchida I, Naito Y, Kureha K, Tujimura M, Sato K. Deep diving behavior of the loggerhead turtle near the frontal zone. Nippon Suisan Gakkaishi. 1990;56(9):263-1443

28. Storch S, Hays GC, Hillis-Starr Z, Wilson RP. The behaviour of a hawksbill turtle data-logged during the passage of hurricane Georges through the Caribbean. Mar Freshw Behav Physiol. 2006;39(4):307-13.

29. Wilson M, Tucker AD, Beedholm K, Mann DA. Changes of loggerhead turtle (Caretta caretta) dive behavior associated with tropical storm passage during the inter-nesting period. J Exp Biol. 2017;220(19):3432-41.

30. Hass T, Hyman J, Semmens BX. Climate change, heightened hurricane activity, and extinction risk for an endangered tropical seabird, the blackcapped petrel Pterodroma hasitata. Mar Ecol Prog Ser. 2012;454:251-61.

31. Bugoni L, Sander M, Costa ES. Effects of the first southern Atlantic hurricane on Atlantic petrels (Pterodroma incerta). Wilson J Ornithol. 2007;119(4):725-9.

32. Lamb JS, Satgé YG, Jodice PGR. Influence of density-dependent competition on foraging and migratory behavior of a subtropical colonial seabird. Ecol Evol. 2017 7(16):6469-81.

33. Jodice PGR, Tavano J, Mackin W. Chapter 8: marine and coastal birds and bats. In: Michel J, editor. South Atlantic information resources: data search and literature synthesis. U.S. Department of the Interior, Bureau of Ocean Energy Management, regulation, and enforcement, Gulf of Mexico OCS region, vol. 01157. New Orleans: OCS study BOEM; 2013. p. 475-587.

34. Phillips RA, Xavier JC, Croxall JP. Effects of satellite transmitters on albatrosses and petrels. Auk. 2003;120:1082-90.

35. Lamb JS, Satgé YG, Fiorello CV, Jodice PGR. Behavioral and reproductive effects of bird-borne data logger attachment on Brown pelicans (Pelecanus occidentalis) on three temporal scales. J Ornithol. 2017;158(2):617-27.

36. Schnell GD, Hellack JJ. Flight speeds of Brown pelicans, chimney swifts, and other birds. Bird-Banding. 1978;49(2):108-12.

37. Duong, T. (2017). Ks: kernel smoothing. R package version 1.10.7.https:// CRAN.R-project.org/package $=$ ks

38. Garriga J, Palmer JRB, Oltra A, Bartumeus F. Expectation-maximization binary clustering for behavioural annotation. PLoS One. 2016;11(3):1-26. 
39. Bennison A, Bearhop S, Bodey TW, Votier SC, Grecian WJ, Wakefield ED, et al. Search and foraging behaviors from movement data: a comparison of methods. Ecol Evol. 2018;8(1):13-24.

40. Afán I, Navarro J, Grémillet D, Coll M, Forero MG. Maiden voyage into death: are fisheries affecting seabird juvenile survival during the first days at sea? $\mathrm{R}$ Soc Open Sci. 2019;6(1):181151.

41. de Grissac S, Bartumeus F, Cox SL, Weimerskirch H. Early-life foraging: behavioral responses of newly fledged albatrosses to environmental conditions. Ecol Evol. 2017;7(17):6766-78.

42. Croissant Y. mlogit: multinomial logit model. R package version. 2013;0:2-4 https://CRAN.R-project.org/package=mlogit.

43. Udyawer V, Read M, Hamann M, Simpfendorfer CA, Heupel MR. Effects of environmental variables on the movement and space use of coastal sea snakes over multiple temporal scales. J Exp Mar Biol Ecol. 2015;473:26-34.

44. Breuner CW, Sprague RS, Patterson SH, Woods HA. Environment, behavior and physiology: do birds use barometric pressure to predict storms? J Exp Biol. 2013;216:1982-90.

45. Metcalfe J, Schmidt KL, Bezner Kerr W, Guglielmo CG, MacDougallShackleton SA. White-throated sparrows adjust behaviour in response to manipulations of barometric pressure and temperature. Anim Behav. 2013; 86(6):1285-90

46. Hainsworth FR. Induced drag savings from ground effect and formation flight in brown pelicans. J Exp Biol. 1988;135:431-44.

47. Spear LB, Ainley DG. Flight speed of seabirds in relation to wind speed and direction. Ibis. 1997;139(2):234-51.

48. Spear LB, Ainley DG. Flight behavior of seabirds in relation to wind direction and wing morphology. Ibis. 1997b;139(2):221-33.

49. Knutson TR, Sirutis JJ, Zhao M, Tuleya RE, Bender M, Vecchi GA, et al. Global projections of intense tropical cyclone activity for the late twenty-first century from dynamical downscaling of CMIP5/RCP4. 5 scenarios. J Clim. 2015:28(18):7203-24.

\section{Publisher's Note}

Springer Nature remains neutral with regard to jurisdictional claims in published maps and institutional affiliations.

Ready to submit your research? Choose BMC and benefit from:

- fast, convenient online submission

- thorough peer review by experienced researchers in your field

- rapid publication on acceptance

- support for research data, including large and complex data types

- gold Open Access which fosters wider collaboration and increased citations

- maximum visibility for your research: over $100 \mathrm{M}$ website views per year

At BMC, research is always in progress.

Learn more biomedcentral.com/submissions 